Suzana Kalckmann 1

Tania Giacomo do Lago 1

Regina Maria Barbosa 1

Wilza Villela 1

Samuel Goihman 2

\section{O diafragma como método contraceptivo: a experiência de usuárias de serviços públicos de saúde}

\author{
The diaphragm as a contraceptive method in the \\ experience of users in the public health services
}

1 Núcleo de Investigação em Saúde da Mulher e da Criança, Instituto de Saúde, Secretaria de Estado da Saúde de São Paulo. Rua Santo Antônio 590, 20 andar, São Paulo, SP 01314-000, Brasil. nisms@saude.sp.gov.br 2 Universidade Federal de São Paulo. Rua Pedro de Toledo 590, São Paulo, SP 04039-000, Brasil. goihman.caid@epm.br
A bstract This study, started in August 1989, describes the acceptability of diaphragms as part of the daily routine of 194 women enrolled at five public health care centers in Osasco, (Greater São Paulo). Follow-up of the cohort was performed by semestral home interviews until August 1991. Our data indicate that the diaphragm can be a viable alternative within the public health care setting. Women, including those from low-income groups, are interested in new al ternatives to currently available contraceptive practices. Nevertheless, the cumulative rate of continuity for use of the method was only $25.7 \%$ ( 39 women) after a period of 12 months. Only $37.1 \%$ of women opting for the diaphragm confirm its use during every act of sexual intercourse. Most of the women (72.7\%) only learned about diaphragms during the process of choosing a contraceptive method. The main reasons for discontinued use were partners' complaints, discomfort, and difficulty in handling. The findings point to the need for reformulating family planning activities to provide greater support for women, introduce initiatives to enhance male participation, and promote on-going training of health professi onal s with regard to the management of the method and support for its users.

Key words Diaphragm; Family Planning; Contraceptive Agents

Resumo Este estudo objetiva descrever como o diafragma foi incorporado ao cotidiano de 194 mulheres que o escol heram como contraceptivo, em cinco servi ços públi cos da região de Osasco, Grande São Paulo, no período de agosto de 1989 a agosto de 1991. O seguimento dessa coorte foi real izado por meio de entrevistas domi ciliares semestrais. Constatou-se que o diafragma pode ser uma escolha viável, pois as mulheres, mesmo as de baixa renda, interessam-se por inovações que possam representar alternativas às suas práticas contraceptivas. No entanto, a taxa acumulada de continuidade de uso aos 12 meses foi de 25,7\%; após 365 dias, 39 mulheres mantiveram o seu uso contínuo. Do total de mulheres que escol heram o diafragma, 37,1\% referiram usá-lo em todas as rel ações durante o período de observação. Os resultados mostram a necessi dade de os serviços readequarem a atividade de planejamento familiar, no sentido de dar um maior suporte às mul heres que optaram pelo diafragma, envolvendo seus parcei ros nesta tomada de decisão. Além disso, a equi pe de planejamento familiar da unidade também precisaria de um reforço contínuo visando aprimorar as técnicas de medição e o apoi o à mulher frente as suas dificuldades iniciais com o método.

Palavras-chave Diafragma; Planejamento Familiar; Anticoncepcionais 


\section{Introdução}

O desejo de controlar o número de filhos e a época de tê-los vem de tempos remotos. O que tem mudado ao longo da história são as condições, os meios, os objetivos e os protagonistas das ações de controle da fecundidade (Petckesky, 1985). Em termos gerais, é possível afirmar que a atividade de controlar os nascimentos praticamente sempre existiu, através de regras que governam o casamento, do infanticídio, de tabus que impediam relações sexuais em determinados períodos e também por meio do aborto e de técnicas contraceptivas.

Os avanços tecnológicos têm colocado à disposição das mulheres um leque crescente de alternativas contraceptivas. Entretanto, os efeitos colaterais, as dificuldades de acesso e de manuseio de muitos destes produtos permitem afirmar que ainda não foi desenvolvido um método que, ao mesmo tempo, atenda às necessidades de contracepção e seja universalmente inócuo à saúde. Embora atual mente a contracepção faça parte do cotidiano da maioria das mulheres, nem sempre é adequada, eficaz e sem problemas. No Brasil, por exemplo, está restrita basicamente à laqueadura eà pílula, adotadas por $40,2 \%$ e $20,7 \%$, respectivamente, das mulheres brasileiras, em união, de 15 a 54 anos de idade. Os métodos vaginais (diafragma, espumas e óvulos) em conjunto são usados por apenas $0,1 \%$ dessas mulheres (DHS $\&$ Bemfam, 1996).

O diafragma - método de barreira, descrito em 1880 pelo médico alemão Hasse, é reconhecido como um anticoncepcional eficaz eque não provoca efeitos sistêmicos. Sua aceitabilidade, entretanto, é bem variável, dependendo da época, do país, e do incentivo que é dado ao seu uso. Segundo Weidegger, em 1961, o diafragma representava $64 \%$ das escolhas em Clínicas de Planejamento Familiar dos EUA (Population Report, 1985).

Entre nós, diafragma nunca atingiu números significativos, exceto em al guns serviços especiais, como: SOS Corpo de Recife, Coletivo Sexualidade e Saúde de São Paulo (ONGs feministas) e Cemicamp, sendo praticamente desconhecido tanto pela população, quanto pelos profissionais de saúde (Villela et al., 1988; Araújo et al., 1993). Conseqüentemente os estudos sobre a sua aceitabilidade e uso são em número reduzido.

No entanto, o surgi mento da AIDS nos anos 80 e seu crescimento entre as mulheres em idade reprodutiva, por transmissão sexual, vem impondo a necessidade de compreender meIhor como lidar com métodos que exigem mu- danças comportamentais. Vale ressaltar que os profissionais de saúde durante décadas receberam a informação que os métodos de barreira "são de baixa eficácia" e "inapropriados para populações de baixa renda", o que os torna pouco hábeis para dar as orientações necessárias para seu uso.

Entender a relação da mulher com o diafragma pode ajudar a esclarecer dificuldades que emergem do uso de outros métodos, como os preservativos masculinos e femininos, cujo uso envolve questões similares, em que pesem suas características específicas. Esse trabal ho representa um esforço para ampliar os conhecimentos sobre o uso do diafragma, considerando a importância atual do uso de métodos de barreiras.

\section{Objetivos}

Descrever a incorporação do diafragma ao cotidiano de usuárias de serviços públicos de saúde, a partir das motivações de escolha, o conhecimento do método e as razões de descontinuidade.

\section{Metodologia}

Este trabal ho utiliza dados de uma investigação mais ampla, que analisou o perfil de escoIha contraceptiva do universo de usuárias de cinco unidades básicas de saúde da regional de saúde de Osasco, região metropolitana de São Paulo, no período de agosto de 1989 a agosto de 1991 (Lago et al., 1995).

Após treinamento da equipe, organização do fluxo e registros, foi desencadeado um processo de monitoramento da atividade de planejamento familiar, a fim de identificar as muIheres a serem incluídas na investigação. Uma mulher foi considerada elegível quando, após passar em consulta médica e em atividade educativa, levou um método para casa com intenção de usá-lo. Além disso, a mulher deveria não estar grávida e aceitar participar do estudo.

A atividade educativa consistia em uma reunião, onde os métodos contraceptivos eram apresentados e discutidos de forma geral, com ênfase nos seus respectivos mecanismos de funcionamento, indicações, vantagens, desvantagens. Durante a atividade educativa eram também esclarecidas as demais dúvidas e dificuldades das mulheres em relação à saúde reprodutiva, verificada a data e o resultado do último papanicolau e feitos os encaminhamentos necessários. Na consulta médica realizada 
após o grupo, a mulher discutia sua preferência de método com o profissional. Caso não houvesse contra-indicação, eram fornecidas as orientações específicas para o uso do método escolhido e fornecido o insumo.

No total, foram incluídas 2.044 mulheres, das quais $210(10,3 \%)$ optaram pelo diafragma. Para todas, independente do método escolhido, foi realizada uma entrevista domiciliar. As que optaram pelo diafragma e pela pílula foram seguidas através de entrevistas semestrais domiciliares.

Do total das que escolheram o diafragma, 194 responderam a primeira entrevista domiciliar e constituíram a coorte analisada neste trabalho. O seguimento domiciliar foi realizado com todas, independente de estarem ou não em uso do diafragma. A gravidez foi o único evento considerado terminal, determinando a saída da mulher do estudo.

Na Figura 1, estão esquematizados os procedimentos desenvolvidos no primeiro ano de seguimento de cada mulher. Elas tiveram tempo de observação distintos devido às diferentes datas de entrada no estudo.

A primeira entrevista domiciliar, realizada num período entre um a dois meses pós escoIha, incluiu questões que permitiam recuperar as histórias contraceptivas e as opiniões sobre os outros métodos, além das informações sócio-demográficas e daquelas referentes ao diafragma.

As entrevistas de seguimento monitoraram as mudanças no cotidiano das mulheres, especialmente quanto ao uso da contracepção. Para tanto foi utilizado um instrumento-Calendário (Kalckmann, 1995), elaborado a partir do proposto por Tietze \& Lewit (1967). O estudo procurou não adotar ou introduzir procedimentos que não fossem possíveis de ser mantidos nas rotinas dos serviços. A análise da dinâmica de uso foi realizada tendo em vista a motivação de escolha, tempo e formas de uso e razões alegadas para a sua descontinuidade.

Considerou-se descontinuidade o não-uso do diafragma por período superior a trinta dias consecutivos, tendo havido relações sexuais.

\section{Resultados e comentários}

Aceitabilidade

A proporção de mulheres que decidiu usar o diafragma neste estudo - 10,3\% do total - foi mais alta que a referida para a população feminina em geral (Arruda et al., 1987; DHS \& Bemfam, 1996), atingindo um número próximo ao
Figura 1

Fluxo da coorte de mulheres que optaram pelo uso do diafragma.

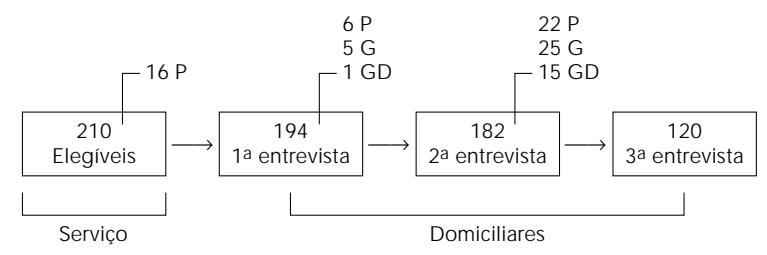

P - perdas

G - gravidez em não-uso de diafragma

GD - gravidez em uso de diafragma

encontrado em serviços especiais: SOS Corpo e Coletivo Feminista Sexualidade e Saúde (Bandler, 1990; Araújo et al., 1993).

As mulheres que escolheram o diafragma eram na sua maioria de baixa renda, com nível médio de escolaridade e coabitando com parceiro. Expressaram desejo por famílias pouco numerosas, sendo o número ideal de filhos dois para $52,6 \%$; três para $16 \%$; um para $13,9 \%$ e nenhum para $8,2 \%$ - com base nas condições que imaginam necessárias para a sua educação. A Tabela 1 apresenta al gumas características sócio-demográficas das mulheres que escolheram o diafragma.

\section{Continuidade de uso}

O processo de aceitabilidade de um método inclui os três primeiros meses de uso, que permitem à mulher confrontar suas informações e expectativas com a realidade de seu cotidiano, sendo, por isso, o período crítico para a manutenção de qualquer método. Neste estudo, durante o primeiro mês pós-escolha, $31,4 \%$ das mulheres interromperam o uso do diafragma e $19 \%$ nos dois meses subseqüentes (Tabela 2). A análise de sobrevivência apresentada na Figura 2 mostra que a taxa de continuidade, ao final de 12 meses, foi de $25,7 \%$ (39). Essa taxa foi menor do que a relatada por outros estudos nacionais: Coletivo 69,4\%, Unicamp 63,5\% e Clínica de Belo Horizonte 85,2\% (Araújo et al., 1993), o que sugere diferenças metodológicas, de análise e conceituais entre os diferentes estudos.

Motivação da escolha

A atividade de planejamento familiar nos serviços incluídos no estudo foi desenvolvida de acordo com as diretrizes propostas pelo PAISM: todas as mulheres participaram do grupo educativo e passaram por consulta ginecológica; $86,1 \%$ fizeram exame Papanicolau antes de le- 
Tabela 1

Características sócio-demográficas na entrevista inicial

\begin{tabular}{|c|c|c|c|c|c|c|}
\hline Idade (anos) & $15-20$ & $20-30$ & $30-40$ & $40-50$ & & Total \\
\hline $\mathrm{n}$ & 12 & 116 & 55 & 11 & & 194 \\
\hline$\%$ & 6,2 & 59,8 & 28,3 & 5,7 & & 100,0 \\
\hline Escolaridade (anos de estudo) & 0 & $1-4$ & $4-8$ & $8-11$ & $>11$ & \\
\hline $\mathrm{n}$ & 10 & 29 & 79 & 54 & 22 & 194 \\
\hline$\%$ & 5,2 & 14,9 & 40,8 & 27,8 & 11,3 & 100,0 \\
\hline Cor & Branca & Parda & Negra & & & \\
\hline $\mathrm{n}$ & 110 & 54 & 30 & & & 194 \\
\hline$\%$ & 56,7 & 27,8 & 15,5 & & & 100,0 \\
\hline Religião & Católica & Protestante & Espírita & S/religião & & \\
\hline $\mathrm{n}$ & 131 & 44 & 2 & 17 & & 194 \\
\hline$\%$ & 67,5 & 22,7 & 1,0 & 8,8 & & 100,0 \\
\hline Origem & Urbana & Rural & & & & \\
\hline $\mathrm{n}$ & 114 & 80 & & & & 194 \\
\hline$\%$ & 58,8 & 41,2 & & & & 100,0 \\
\hline Nascimento & Norte & Nordeste & Sudeste & Sul & C. Oeste & \\
\hline $\mathrm{n}$ & 8 & 52 & 106 & 26 & 2 & 194 \\
\hline$\%$ & 4,1 & 26,8 & 54,7 & 13,4 & 1,0 & 100,0 \\
\hline Parceiro Fixo & Coabita & N/coabita & $\mathrm{Não}$ tem & & & \\
\hline $\mathrm{n}$ & 171 & 15 & 8 & & & 194 \\
\hline$\%$ & 88,2 & 7,7 & 4,1 & & & 100,0 \\
\hline $\mathrm{N}$ o Filhos vivos & 0 & 1 & 2 & $>3$ & & \\
\hline$n$ & 25 & 66 & 69 & 34 & & 194 \\
\hline$\%$ & 12,9 & 34,0 & 35,5 & 17,5 & & 100,0 \\
\hline Desejo de gravidez futura & $\operatorname{Sim}$ & Não & Dúvida & & & \\
\hline $\mathrm{n}$ & 86 & 97 & 11 & & & 194 \\
\hline$\%$ & 44,3 & 50,0 & 5,7 & & & 100,0 \\
\hline Tempo de relação ${ }^{1}$ (meses) & $1-12$ & $12-36$ & $36-60$ & $60-120$ & $120-350$ & \\
\hline $\mathrm{n}$ & 14 & 34 & 42 & 52 & 44 & 186 \\
\hline$\%$ & 7,5 & 18,3 & 22,6 & 28,0 & 23,6 & 100,0 \\
\hline Trabalho remunerado & Sim & Não & & & & \\
\hline $\mathrm{n}$ & 95 & 99 & & & & 194 \\
\hline$\%$ & 49,0 & 51,0 & & & & 100,0 \\
\hline $\begin{array}{l}\text { Indicador sócio-econômico } \\
\text { Aba/Abipeme }\end{array}$ & $A / B$ & C & $\mathrm{D}$ & $E$ & & \\
\hline $\mathrm{n}$ & 12 & 43 & 89 & 50 & & 194 \\
\hline$\%$ & 6,2 & 22,1 & 45,9 & 25,8 & & 100,0 \\
\hline
\end{tabular}

1 Excluídas oito mulheres que estavam sem parceiro fixo no início do estudo. 
var o método e 91,2\% receberam material educativo.

$\mathrm{Na}$ entrevista inicial, as mulheres declararam ter ouvido falar na maioria dos métodos contraceptivos: $100 \%$ da pílula; $99,5 \%$ do coito interrompido; $99,5 \%$ do condom; $98,5 \%$ da laqueadura; $86,1 \%$ do DIU. No entanto, o diafragma, os espermicidas e o método de Billings eram praticamente desconhecidos, e $72,7 \%$ ouviu falar do diafragma pela primeira vez nos grupos educativos que antecediam a consulta médica. Isso significa que o conhecimento sobre o diafragma foi fornecido pelos profissionais de saúde, sem que a mulher dispusesse de outros suportes ou informações sobre o método a partir de seu círculo de relações, o que deve ser considerado na avaliação dos resultados do projeto.

Das mulheres que optaram pelo diafragma, $96,4 \%$ tinham experiência anterior de contracepção, iniciada com o uso da pílula $(66,9 \%)$ e do coito interrompido (19,6\%). Uma mulher já havia usado o diafragma anteriormente.

A análise do uso contínuo e isolado de cada método no passado evidencia o predomínio de períodos menores de um ano, e apenas uma parcela das usuárias da pílula (75\%) manteve o seu uso por pelo menos um ano.

No total, $26,3 \%$ das mulheres referiram ao menos uma gravidez em uso de contracepção. Destas, 45,3\% foram atribuídas à fal ha da pílula, apesar de, contraditoriamente, esta ser considerada pelo grupo o método mais eficaz. $\mathrm{O}$ coito interrompido e a tabelinha foram responsabilizados por, respectivamente, 30\% e 15\% destas gestações. Em síntese, esses dados apontam para uma experiência contraceptiva no passado restrita e insatisfatória.

No processo de escolha, alguns métodos nem foram pensados como possibilidades, porque as mulheres imaginavam ou sabiam que seus parceiros não concordariam com o seu uso. Segundo as entrevistadas, eles não aceitariam métodos masculinos, como a vasectomia, rejeitada por $73,1 \%$, e o condom, por $36,6 \%$. É interessante observar que $100 \%$ dos parceiros não fariam restrição à laqueadura e apenas 1,1\% fariam restrição ao coito interrompido.

As mulheres escolheram o diafragma esperando encontrar: ausência de efeitos colaterais e proteção à saúde (39,7\%); praticidade e facilidade de uso (34,0\%); eficácia $(21,1 \%)$ e uma boa solução para a baixa freqüência de relações sexuais (9,8\%). Além disso, 11,3\% referiram o fato de o diafragma ser uma alternativa nova, que despertou a vontade de experimentar. Para 28,9\%, a escolha foi por exclusão das outras possibilidades contraceptivas e $8,8 \%$ va-
Tabela 2

Interrupção de uso e taxas de descontinuidade de acordo com o período de ocorrência.

\begin{tabular}{lcccc}
\hline Interrupção & \multicolumn{4}{c}{ Período de interrupção (dias) } \\
& $0-30$ & $30-90$ & $90-180$ & $180-365$ \\
\hline Sim & 61 & 24 & 35 & 19 \\
Não & 133 & 103 & 68 & 39 \\
Total & 194 & 127 & 103 & 58 \\
Taxa de descontinuidade & 31,4 & 18,9 & 34,0 & 32,8 \\
\hline
\end{tabular}

\section{Figura 2}

Curva de sobrevida de interrupção de uso do diafragma.

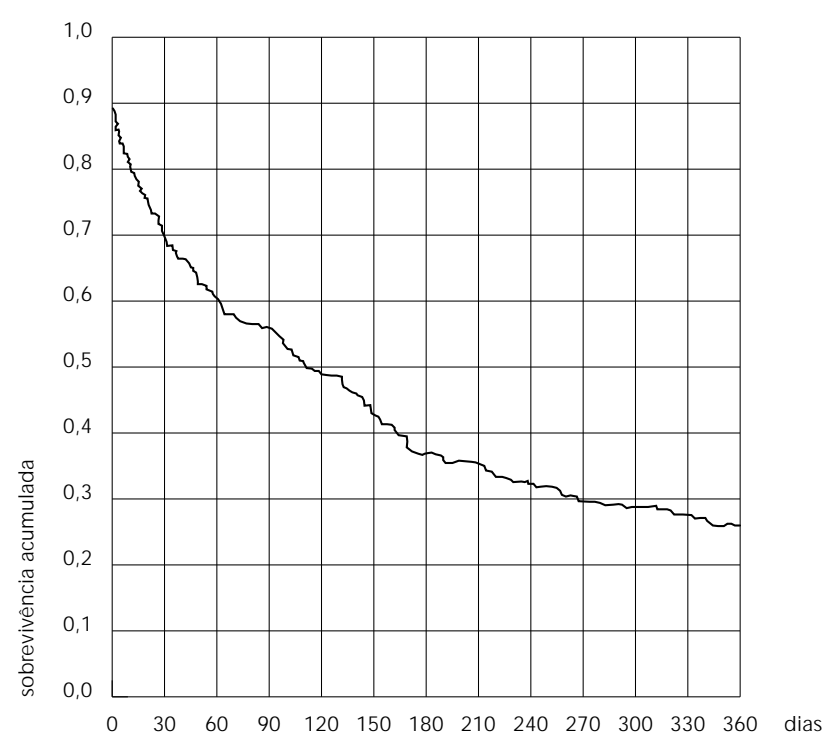

lorizaram o maior controle da mulher na contracepção conferida pelo diafragma.

Se todos os métodos estivessem igualmente disponíveis ou indicados, o diafragma seria o método preferencial para $66,5 \%$. Entre aquelas que preferiam ter usado outro método, $44,6 \%$ queriam laqueadura, $20 \%$, vasectomia e $24,6 \%$ o DIU, métodos definitivos ou de alta eficácia, desvinculados do intercurso sexual. Portanto, de natureza oposta ao diafragma.

\section{Conhecimento sobre o diafragma}

Na entrevista inicial, 91,8\% das mulheres afirmaram que o diafragma atua como uma barreira mecânica à entrada dos espermatozóides; $99,5 \%$ sabiam que deveria ser usado associado a um creme ou gel, embora $20 \%$ não soubessem que este uso tinha por função aumentar a 
eficácia contraceptiva do método: 14,9\% acreditavam que a sua função era aumentar a lubrificação e 6,2\% não sabiam por que usá-lo.

Do total, 92,8\% sabiam que deviam usá-lo a cada relação e $84,0 \%$ que deviam colocá-lo até duas horas antes da relação. É curioso que $10,3 \%$ das mulheres pensavam que ele deveria, obrigatoriamente, ser colocado pelo menos duas horas antes da relação.

O tempo adequado para a sua retirada, mínimo de seis e máximo de 24 horas após a relação sexual, era conhecido por 85,6\% da mulheres, e nenhuma apontou tempo máximo superior a 24 horas. Do total, 71,1\% tinham domínio de todas as recomendações de uso fornecidas pelo estudo, isto é que o diafragma deve ser usado em todas as relações, com espermicida, que sua inserção não pode exceder o período de até duas horas antes da relação e sua retirada em tempo mínimo de seis e máximo de 24 horas pós-relação.

\section{Uso do diafragma}

Ao longo do seguimento, foi verificado que as práticas de uso eram discrepantes com o nível de conhecimentos: o diafragma foi usado de forma consistente e adequada por $32,4 \%$ das mulheres, durante o período de observação. A adequação de uso foi avaliada segundo regularidade, uso do espermicida e obediência aos tempos de colocação e retirada do método (Tabela 3).

Tabela 3

Síntese das formas de uso do diafragma como método contraceptivo ${ }^{1 .}$

\begin{tabular}{|c|c|c|c|c|c|c|}
\hline Uso diafragma & Adequado & Inadequado & Não-uso & & & Total \\
\hline $\mathrm{n}$ & 61 & 106 & 21 & & & 188 \\
\hline$\%$ & 32,4 & 56,4 & 11,2 & & & 100,0 \\
\hline Dificuldade colocar & Sim & Não & S/inf. & & & \\
\hline$n$ & 31 & 139 & 18 & & & 188 \\
\hline$\%$ & 16,5 & 73,9 & 9,6 & & & 100,0 \\
\hline Dificuldade retirar & Sim & Não & S/inf. & & & \\
\hline$n$ & 35 & 133 & 20 & & & 188 \\
\hline$\%$ & 18,6 & 70,7 & 10,6 & & & 100,0 \\
\hline Regularidade uso 2 & Constante & Intermitente & & & & \\
\hline$n$ & 77 & 90 & & & & 167 \\
\hline$\%$ & 46,1 & 53,9 & & & & 100,0 \\
\hline Uso associado2 & $\begin{array}{l}\text { Diafragma } \\
\text { c/espermicida }\end{array}$ & Outros métodos & & & & \\
\hline$n$ & 99 & 68 & & & & 167 \\
\hline$\%$ & 59,3 & 40,7 & & & & 100,0 \\
\hline Método associado 3 & Coito interrompido & Condom & Ducha & Pílula & Tabela & \\
\hline $\mathrm{n}$ & 32 & 7 & 1 & 9 & 19 & 68 \\
\hline$\%$ & 47,1 & 10,3 & 1,5 & 13,2 & 27,9 & 100,0 \\
\hline $\begin{array}{l}\text { Uso espermicida2 } \\
\text { n }\end{array}$ & $\begin{array}{c}\text { Sempre c/reposição } \\
111\end{array}$ & $\begin{array}{c}\text { Sempre s/reposição } \\
36\end{array}$ & $\begin{array}{c}\text { Intermitente } \\
20\end{array}$ & & & 167 \\
\hline$\%$ & 66,4 & 21,6 & 12,0 & & & 100,0 \\
\hline Tempo colocação 2 & Durante relação & A té $2 \mathrm{~h}$ antes & Mais $2 \mathrm{~h}$ antes & & & \\
\hline$n$ & 72 & 65 & 30 & & & 167 \\
\hline$\%$ & 43,1 & 38,9 & 18,0 & & & 100,0 \\
\hline Tempo retirada 2 & $<6 \mathrm{~h}$ & 6 a $8 h$ & $>8 \mathrm{~h}$ & & & \\
\hline$n$ & 14 & 127 & 26 & & & 167 \\
\hline$\%$ & 8,4 & 76,0 & 15,6 & & & 100,0 \\
\hline
\end{tabular}

1 Excluídas seis mulheres não acessadas na entrevista domiciliar de seis meses.

2 Excluídas 21 mulheres que não utilizaram o diafragma no intercurso sexual.

3 Excluídas 120 mulheres que utilizavam apenas o diafragma. 
A irregularidade de uso foi o problema mais freqüente (54\%), explicitando dificuldades para o estabelecimento de uma rotina necessária à sua utilização. Este uso irregular foi atribuído à própria natureza do método: "ter que levantar para colocar", "senti preguiça de colocar", "não tinha programado a relação", "estava muito cansada", "não deu tempo", "ele não queria esperar".

Entre as mulheres que faziam uso alternado do diafragma com outras práticas, foram identificados quatro padrões: restrição do diafragma ao período que consideravam fértil $(27,9 \%)$ e não-uso de proteção nos outros dias; alternância de uso com o coito interrompido (47,1\%); com o condom e uso concomitante da pílula. Os dois primeiros são particularmente complicados, do ponto de vista da eficácia, quando se constata que apenas 39,7\% eram capazes de identificar corretamente o período fértil e que $38,7 \%$ acreditavam que poderiam ficar grávidas durante a menstruação e/ ou nos dias próximos a ela.

O espermicida foi usado por $88,1 \%$ das muIheres; no entanto, $21,6 \%$ delas não realizavam a sua reposição, em relações sexuais sucessivas. Para $12,0 \%$ das mulheres que usaram o espermicida de forma intermitente, este foi um problema, sendo referidas 'reações alérgicas'; dificuldades com mudanças de marcas; dependência dos serviços para reposição; rejeição do parceiro ao excesso de lubrificação ou do cheiro; impedimento para sexo oral.

Cerca da $80 \%$ das mulheres colocava e retirava o método segundo as orientações recebidas: durante a relação sexual, até 15 minutos antes da penetração ou até duas horas antes; $76 \%$ retiravam-no de seis a oito horas após. Contudo, 18,1\% colocavam-no em período de tempo maior que duas horas antes da relação; $8,4 \%$ retiravam-no precocemente (antes de seis horas pós-relação) e 15,7\% mantinham-no por tempo superior a oito horas pós-relação.

Alguns relatos mostram que algumas práticas inadequadas são resultados de equívocos no uso da informação - "énecessário colocar o diafragma muito antes da relação" -; assim, caso o diafragma não fosse colocado pelo menos duas horas antes, "não valia mais a pena colocá-lo"; "tinha que ficar pelo menos 12 horas com o diafragma depois da relação, então nos dias que trabal hava na feira, não usava".

A fragmentação das informações tem contornos dramáticos em alguns casos, como o de uma jovem que ficou grávida em uso do diafragma: sabia que devia fazer reposição de espermicida quando tinha relações sucessivas e tinha tanto medo de gravidez que obedecia ce- gamente às regras: retirava o diafragma após a primeira ejaculação, fazia a reposição e continuava. A análise desses relatos indica que a decodificação das orientações recebidas é, por vezes, realizada de forma distorcida, por falta de outros conhecimentos anteriores e/ ou mais amplos. Percebe-se que al gumas regras são decoradas sem, contudo, serem entendidas e incorporadas.

Apesar da irregularidade do uso e da alta taxa de abandono, 64,7\% das que interromperam seu uso e $97,4 \%$ das que o mantiveram reconheceram vantagens no diafragma. As que interromperam valorizaram seus atributos de não provocar efeitos colaterais, ser seguro e não interferir na relação, citados por 32,4\%, $16,5 \%$ e $7,9 \%$, respectivamente. Como esperado, as que o mantiveram perceberam mais vantagens: não provocar efeitos colaterais $(66,7 \%)$; ter se mostrado eficaz ( $51,3 \%)$; ser prático $(20,5 \%)$ e seu uso ser restrito à relação $(20,5 \%)$.

A proporção de mulheres que apontou desvantagens do diafragma foi similar entre as que interromperam e as que mantiveram o uso, $69,1 \%$ e $64,1 \%$, respectivamente. A queixa de que o método é trabalhoso foi referida por $22,3 \%$ das primeiras e por $41,0 \%$ das demais. As que interromperam o uso consideraram, como desvantagens, incomodar o parceiro $(20,9 \%)$; interferir na relação $(13,7 \%)$; ser difícil de manusear (11,5\%); ser incômodo (11,5\%); ter baixa eficácia (10,1\%). Entre as que se mantiveram em uso, $12,8 \%$ não gostaram do espermicida; 7,7\% tinham nojo em manuseá-lo; 10,3\% não confiavam em sua eficácia. Assim, em relação às desvantagens apontadas, o que diferencia estas mulheres é que as que aderem ao método não referem incômodo com o seu uso e apenas $2,6 \%$ citaram queixas por parte dos parceiros.

Não ocorreu interferência do método no exercício da sexualidade para $59,4 \%$ das muIheres que mantiveram o uso e $57,9 \%$ das que interromperam. Para $19,4 \%$ e $13,2 \%$ respectivamente, houve uma interferência negativa e $11,5 \%$ e $28,9 \%$ fizeram referência a mudanças positivas, melhorando o desempenho sexual do casal. Os dados sugerem que uma interferência negativa no exercício da sexualidade contribui para a redução do tempo de uso; contudo, mais da metade das mulheres $(50,8 \%)$ não respondeu a essa questão.

Entre as que mantiveram o uso, $48,7 \%$ referiram problemas como: incômodo (17,9\%) má impressão, dores vagas, prisão de ventre, dores na 'barriga' ou 'por baixo'; queixas sugestivas de infecção urinária (10,2\%) e agravamento de problemas anteriores - Bartolinite, 'ferida' no colo do útero, inflamação nas trompas. É in- 
teressante observar que algumas mulheres citam dificuldades iniciais com o manuseio do diafragma, só vindo a incorporá-lo a partir do segundo mês de uso.

Problemas como o incômodo foram vividos tanto pelas que mantiveram o uso, como pelas que descontinuaram, sugerindo que as primeiras conseguiram formas para contorná-los ou resolvê-los. Outros problemas, como a resistência do parceiro, levaram sistematicamente à interrupção.

Apesar de terem sido avisadas da possibilidade de consultas eventuais, nem sempre as mulheres retornaram aos serviços para tirarem dúvidas, receberem novas orientações ou treinarem melhor o manuseio do método. A menor proporção de procura $(54,5 \%)$ ocorreu entre as que descontinuaram precocemente (0-29 dias) e a maior entre as que se mantiveram em uso $(84,2 \%)$. Chama atenção o fato de que as mulheres que mantiveram o uso do diafragma, em maior proporção que as demais, tenham buscado o serviço de saúde para solucionar dúvidas ou dificuldades com o método, sendo atendidas de forma satisfatória.

Além disso, as mulheres que escolheram o diafragma como a alternativa preferencial tiveram menor taxa de descontinuidade do que as mulheres que ficaram com o diafragma por não terem disponível o seu método de escolha.
Interrupção de uso

Nesse estudo, as razões alegadas para a primeira interrupção do diafragma foram analisadas por períodos de ocorrência. Os períodos analisados foram: 0-29 dias; 30-89 dias; 90-179; 180365 dias (Figura 3).

Como pode ser observado pela Figura 3, a razão apontada pela maioria (30,2\% do total), em todos os períodos considerados, foi a falta de apoio ou queixa por parte dos parceiros: 34,4\% (0-29 dias); 29,2\% (30-89 dias); $25,7 \%$ (90-179 dias) e $26,3 \%$ ( $180-365$ dias).

A dificuldade de manuseio, especialmente o medo de retirar o diafragma, teve papel importante nos primeiros dias de uso, sendo a razão apontada por 21,3\% (0-29 dias) e 12,5\% (30-89 dias).

Uma proporção significativa de mulheres $(18,0 \%)$ atribuiu a interrupção a 'dores' (vaginais, abdominais e no períneo) e incômodo com o método colocado, sugerindo que pode ter ocorrido, neste estudo, problemas na medição do diafragma (Figura 4).

Comparando a nossa distribuição de tamanhos com a de outros estudos brasileiros, observa-se que as nossas medidas são maiores do que as referidas pelo Coletivo Feminista Sexualidade e Saúde e Clínica de Ginecologia de Belo Horizonte e similares às adotadas na Clínica de Atendimento à Mulher - Unicamp, conforme apresentado na Figura 2.

Figura 3

Razões alegadas para a primeira interrupção de uso do diafragma por períodos de ocorrência.

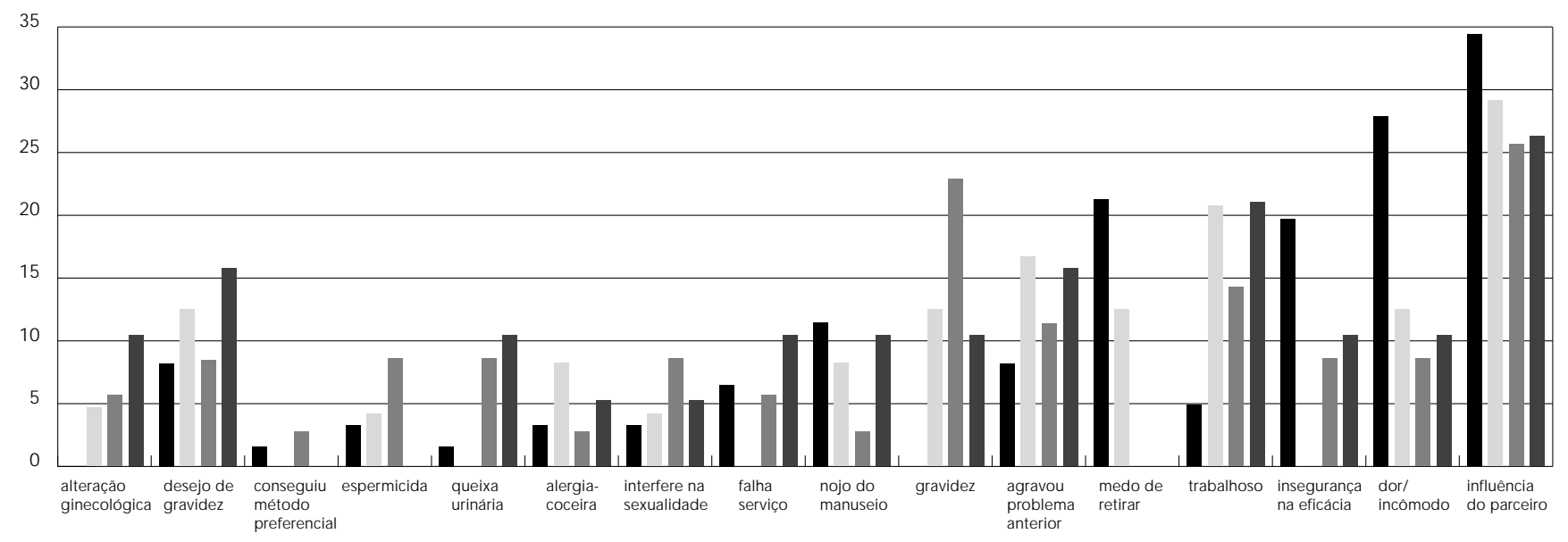

$180-364$ dias $90-179$ dias $\quad 30-89$ dias $0-29$ dias

\footnotetext{
1 respostas múltiplas, consideradas até duas razões por usuária.
} 
Figura 4

Distribuição das medidas do diafragma adotadas por serviço/estudo.

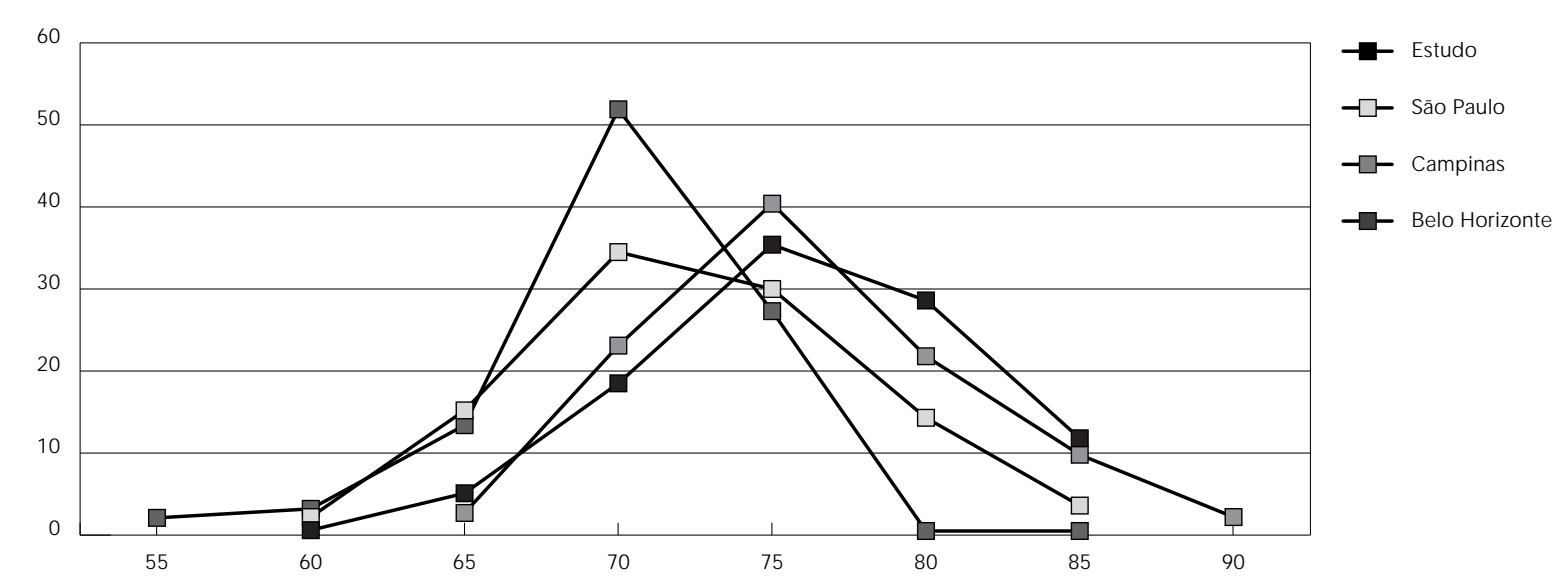

\begin{tabular}{lrrrr} 
Medida do diafragma & Estudo1 & São Paulo & Campinas & B. Horizonte \\
\hline Total & 178 & 223 & 225 & 187 \\
Mediana & 75 & 70 & 75 & 70 \\
Média & 76,10 & 72,60 & 75,98 & 70,187 \\
Intervalo de confiança (95\%) & {$[75,307-76,885]$} & {$[71,895-73,309]$} & {$[75,289-76,667]$} & {$[69,546-70,828]$}
\end{tabular}

1 Excluídas 16 mulheres que não souberam informar o tamanho.

(Kalckmann, 1995; Araújo et al., 1993).

Não se pode esquecer que, para os profissionais de saúde, o diafragma também era uma nova alternativa: a maioria só entrou em contato com ele durante o treinamento. Como refere Goldenberg (1992), não existe nas Escolas Médicas formação adequada sobre o planejamento familiar. Quando abordado, este restringe-se à indicação dos métodos hormonais e de DIUs.

Assim, os profissionais não dispunham de experiência acumulada sobre o método e, de modo geral, não tiveram tempo para sedimentarem e introjetarem a confiança no diafragma. Pelas condutas adotadas, percebe-se que eles oscilavam entre o entusiasmo e a curiosidade para indicá-lo ou apresentá-lo às usuárias e a falta de segurança para apoiar seu uso continuado. Essa falta de experiência pode ter influenciado na adoção de tamanhos maiores do que os adequados, esperando com isso um ganho de efetividade. Isto poderia explicar a alta freqüência de queixas relacionadas à irritação da vagina, interpretada pelas mulheres como alergia ou queixas sugestivas de infecções urinárias. Fihn (1985) refere que o diafragma pode causar cistites recorrentes pela pressão da sua borda superior contra a uretra, principalmente se for maior do que o necessário, sendo sugestivo observar que na Clínica de Belo Horizonte, que acumula experiência com o seu uso e onde são adotados os menores tamanhos, não ocorreram queixas de infecção urinária (Araújo et al., 1993).

\section{Situação após interrupção do diafragma}

Ao interromperem o uso do diafragma, 73,3\% das mulheres passaram para outro método, das quais $35,3 \%$ para a pílula, $35,3 \%$ para o coito interrompido, $19,6 \%$ para o condom, $4,9 \%$ para a tabela, 2,9\% para a 'ducha', 2,0\% para a vasectomia; $17,3 \%$ ficaram sem proteção, das quais apenas a metade com intenção de engravidar. É interessante observar que 24 mulheres tiveram gravidez acidental em uso de outras práticas contraceptivas, após a interrupção do diafragma.

No primeiro ano de seguimento, 13 mulheres referiram ter ficado grávidas em uso do diafragma, no entanto é fundamental ressaltar que apenas duas delas usaram o diafragma de modo correto e consistente. As outras (87,5\%) fizeram uso inadequado do método, predominantemente deixaram de usá-lo em várias relações, no período em que ficaram grávidas. 


\section{Conclusões}

- Tendo sido oferecido, em igualdade de condições aos outros métodos contraceptivos, em serviços públicos de saúde e com usuárias de baixa renda, o diafragma foi escolhido por $10 \%$ das mulheres.

- A maioria das mulheres entrou em contato com o diafragma pela primeira vez durante $o$ processo de escolha. Entre as razões al egadas para a sua adoção destacaram-se: ser inócuo à saúde, ser efetivo e ter praticidade de uso, somado à falta de outras alternativas.

- A insatisfação com a experiência contraceptiva anterior, as restrições impostas pelos parceiros, a não-disponibilidade de métodos definitivos e a exposição recente à atividade educativa influenciaram positivamente a escolha.

- Embora conhecessem as recomendações de uso do diafragma, as usuárias demonstraram muita dificuldade para incorporá-las às suas vidas. A maioria adotou formas de uso discrepantes com as orientações recebidas, dentre as quais predominaram a falta de aderência ao método e a alternância e/ ou associação a outras práticas contraceptivas, como coito interrompido e tabela.

- A discrepância entre o conhecimento e o uso do método sugerem que as informações técnicas fornecidas no início da atividade não foram suficientes para sedimentar as rotinas necessárias ao uso consistente do método.

- Os problemas referidos com maior freqüência foram relacionados a 'estar com o método dentro' e à resistência dos parceiros. Entre as desvantagens atribuídas ao diafragma destacaram-se o trabalho para a sua colocação e as queixas dos parceiros. Como vantagens foram valorizadas a sua inocuidade à saúde e eficácia.

- A escolha, a continuidade de uso e a percepção de problemas e de efeitos colaterais causados pelo diafragma foram permeados por comparações aos métodos conhecidos e já incorporados ao universo feminino, ou seja, pílula, laqueadura, coito interrompido e, em menor escala, a vasectomia.

- Mesmo para esse grupo, que buscou uma prática contraceptiva menos invasiva e medicalizada, a laqueadura e a vasectomia faziam parte de suas pretensões futuras, como se fossem um caminho natural a ser seguido.

- A novidade que o diafragma representa para os serviços e seus profissionais, e os problemas que decorrem da sua inexperiência com o método, aponta para a necessidade de um processo de supervisão e educação continuada nas unidades que pretenderem oferecê-lo sistematicamente.

- A participação em apenas uma sessão de grupo não foi suficiente para dar à mulher segurança quanto ao uso e manuseio do método. Seria necessário um treinamento inicial mais prolongado e aprofundado, assim como a garantia de consultas de retorno e ou de pronto atendimento, no período imediatamente após a escolha, que se mostrou crítico para a manutenção do método.

- É importante buscar formas que facilitem a oferta deste tipo de atividades, considerando, no entanto, a alta demanda desses serviços.

- É fundamental também levar em conta a opinião dos parceiros, facilitando e estimulando a participação dos homens nas atividades de planejamento familiar. 


\section{Referências}

ARAÚJO, M. J. O; FERREIRA, A. E.; REGINA, C. H.; DIAZ, M.; GRILLO, C. S. \& FAÚNDES, A., 1993. Avaliação clínica do diafragma vaginal em três contextos brasileiros. Femina, 21:463-472.

ARRUDA, J. M.; RUTENBERG, N.; MORRIS, L. \& FERRAZ, E. A., 1987. Pesquisa Nacional sobre Saúde Materno-Infantil ePlanejamento Familiar. Rio de Janeiro/ Westinghouse: Bemfam (Sociedade Civil Bem-Estar Familiar no Brasil)/ Columbia Maryland Institute for Resource Development.

BANDLER, R., 1990. Diafragma: Uma Proposta Educativa de Contracepção. Recife: SOS Corpo - Grupo de Saúde da Mulher.

DHS (Demographic and Health Surveys) \& BEM FAM (Sociedade Civil Bem-Estar Familiar no Brasil), 1996. Brasil: Pesquisa Nacional sobre Demografia eSaúde. Relatório Preliminar. Rio de Janeiro: Macro International.

FIHN, S., LATHAM, R. H., ROBERTS, P.; RUNNING, K. \& STAM M , W. E., 1985. Association between diaphragm use and urinary tract infection. Journal of the American Medical Association, 254:240-245.

GOLDENBERG, P., 1992. Contracepção e reprodução social. In: Pesquisa Social em Saúde (A. W. P. Spinola, E. N. C. Sá, M. F. Westphal, R. C. F. Adorno \& F. Zioni, orgs.), pp. 243-256. São Paulo: Editora Cortez.
LAGO, G. T.; BARBOSA, M. R.; KALCKMANN, S.; VILLELA, V. W. \& GOIHMAN, S., 1995. Acceptability of diaphragm among low-income women in São Paulo. International Family Planning Perpectives, 21:114-118.

KALCKMANN, S. A., 1995. Dinâmica de Uso do Diafragma como Método Contraceptivo entre Usuárias de Serviços Públicos. Dissertação de Mestrado, São Paulo: Escola Paulista de Medicina, Universidade Federal de São Paulo.

PETCKESKY, R., 1985. Abortion and Women'S Choice. Boston: University Press.

POPULATION REPORTS, 1985. Novidades em Anticoncepção Vaginal. Série H, n. 7, Baltimore: John Hopkins University.

TIETZE, C. \& LEWIT, S., 1967. Comparison of three contraceptive methods: diaphragm with jelly or cream, vaginal foam and jelly cream alone. The Journal of Sex Research, 3:295-311.

VILELLA, W.; KALCKMANN, S. \& BARBOSA R., 1988. Avaliação do Planejamento Familiar na Grande São Paulo. Relatório Final. São Paulo: Divisão de Saúde Materna e da Criança, Instituto de Saúde. (mimeo.) 